\title{
ÁREAS POTENCIALMENTE PERIGOSAS A ACIDENTES COM TRANSPORTE RODOVIÁRIO DE PRODUTOS PERIGOSOS NO TRECHO ALAGOANO DA RODOVIA BR-101 \\ DANGEROUS AREAS SUBJECT TO ACCIDENTS INVOLVING THE TRANSPORTATION OF HAZARDOUS PRODUCTS IN THE STATE OF ALAGOAS STRETCH OF BR-101 HIGHWAY
}

\author{
${ }^{1}$ Universidade Federal de Alagoas (UFAL), Maceio, AL, Brasil \\ Correspondência para: Esdras Lima Andrade (ezrandrade@gmail.com) \\ doi:10.12957/geouerj.2018.28821 \\ Recebido em: 20 set. 2017 | Aceito em: 15 mai. 2018
}

Esdras de Lima Andrade', Silvana Quintella Cavalcanti Calheiros

\section{$\checkmark$ SCREEEE BY}

\section{RESUMO}

O presente estudo é a primeira de três etapas para identificação de áreas de risco ambientais a acidentes com transporte de produtos perigosos na rodovia BR-101 que atravessa o Estado de Alagoas. Aborda, a integração das variáveis que atuam diretamente na definição de áreas que apresentam perigo à ocorrência de acidentes com transporte rodoviário de produtos químicos. Este trabalho visa identificar essas áreas, buscando entender suas relações com os acidentes. A base de dados utilizada adotou a escala 1:50.000 e foi composta de quatro mapas vetoriais, correspondendo a intensidade pluviométrica, sinuosidade da rodovia, concentração de focos de queimadas, e neblina potencial. Os dados foram convertidos para a estrutura raster, permitindo a integração no software QGIS mediante emprego de análise multicritério baseado em média ponderada. Os resultados mostraram que $42 \%$ da área analisada de 2.370,66 km² corresponde ao nível Médio Potencial, 31\% a Médio Potencial e $27 \%$ ao grau de Baixo Potencial. Concluiu-se que os principais parâmetros responsáveis na determinação dos trechos que apresentam o maior grau de periculosidade foram os índices de intensidade pluviométrica e o de sinuosidade da rodovia.

Palavras-chave: Perigo, geoprocessamento, rodovias, produtos perigosos

\section{ABSTRACT}

This paper is the first of three steps to identify the environmentally high-risk areas subject to accidents involving shipments of hazardous products routed through BR-101 Highway in the State of Alagoas. It addresses the integration of variables that directly define the areas that pose risk to accidents occurrence in which chemical products are transported. In addition to identify these areas, it seeks to understand their relationships with the accidents. The database used the 1:50,000 scale and was composed of four vector maps corresponding to rainfall intensity, sinuosity of the highway, concentration of pockets of wildfires, and potential fog. The data were converted to the raster structure allowing the integration in the QGIS software using a multicriteria analysis based on weighted average. The results showed that $42 \%$ of the analyzed area of 2,370.66 $\mathrm{km}^{2}$ corresponds to the Medium Potential level, 31\% to the Medium Potential and $27 \%$ to the Low Potential level. As a conclusion, the rainfall intensity and the sinuosity of the highway indices were the main parameters responsible for the determination of the stretches which present the highest degree of hazard.

Keywords: Danger, geoprocessing, highways, dangerous products.

\section{INTRODUÇÃO}

A malha rodoviária do Brasil computa aproximadamente 1,72 milhões de quilômetros e concentra cerca de $67 \%$ do volume total das cargas escoadas em todo o território nacional, o que garante a este 
modal o principal sistema de escoamento da produção agrícola e industrial do país (CONFEDERAÇÃO NACIONAL DO TRANSPORTE, 2016; INSTITUTO DE LOGÍSTICA E SUPPLY CHAIN, 2016).

Segundo o anuário estatístico das rodovias federais referente ao ano de 2010 (DNIT, 2011), as vias e estradas de jurisdição federal foi multiplicada em 16,56 vezes, passando de 4.000 em 1952 para 66.247 quilômetros em 2010. Neste mesmo ínterim, a quantidade de acidentes registrou um aumento de $1.046 \%$, ou seja, subindo de 1.748 para 182.900 acidentes (Figura 1 ).

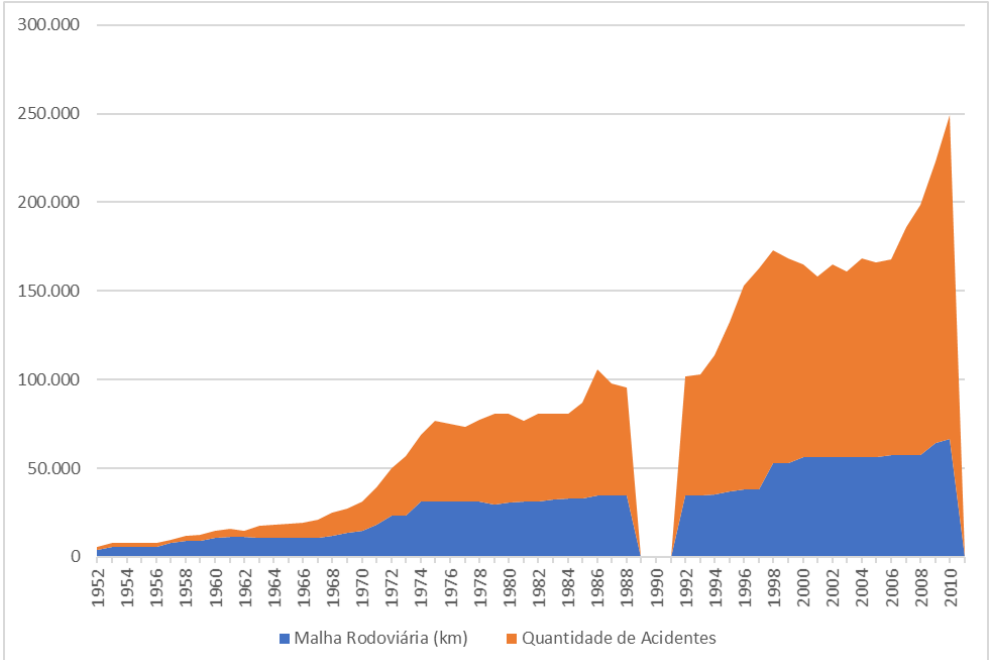

Figura 1. Comparativo do crescimento da malha rodoviária federal e da sua quantidade de acidentes no período compreendido entre 1952 e 2010. Fonte: DNIT (2011)

Ao considerar que a maior parte do transporte de cargas de produtos químicos perigosos é realizado através dessas rodovias, e, ao associá-los à sua natureza potencialmente poluidora, considera-se, portanto, um tema de extrema relevância, merecendo receber especial atenção dos entes públicos competentes.

Diante disso, para DNIT (2011), entre 1957 e 2010 o número de veículos, segundo sua finalidade, envolvidos em acidentes nas rodovias de jurisdição federal, passou de 2.960 para 317.711 , o que corresponde a um crescimento de aproximadamente $10.700 \%$, ao mesmo tempo em que a quantidade de veículos de carga participante em sinistros supera em 41 vezes a importância inicial analisada, ou seja, parte de 1.934 e alcança-se 79.374 veículos (Figura 2). 


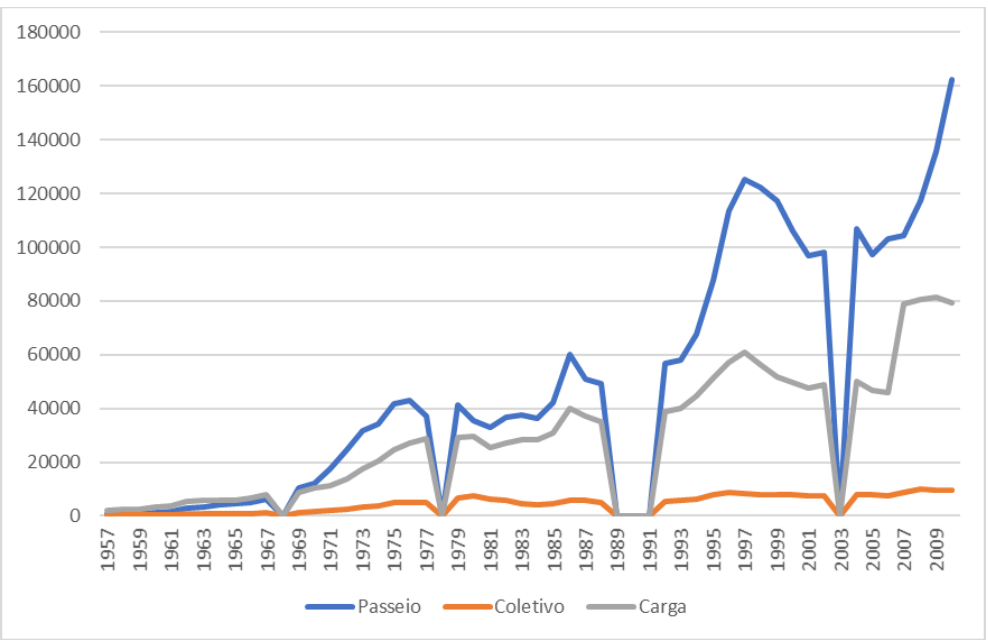

Figura 2. Número de veículos, segundo finalidade, envolvidos em acidentes nas rodovias de jurisdição federal entre 1957 e 2010. Fonte: DNIT (2011).

No entanto, em Alagoas, os números começaram a ser monitorados de maneira efetiva a partir de meados da década de 2000. Daí, no período compreendido entre 2007 e 2011, foram registrados 7.275 acidentes nas rodovias federais, envolvendo 17.133 veículos; dos quais, $28 \%$, ou seja, 4.858 foram caminhões (Figura 3). Destes, apenas 31 (0,64\%) veículos transportavam produtos químicos perigosos.

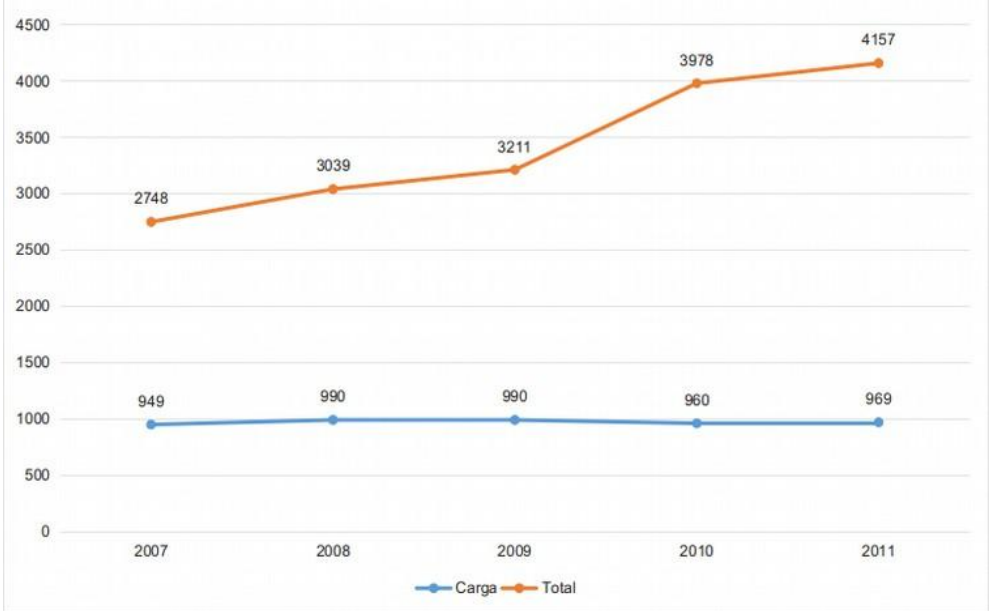

Figura 2. Número de veículos de carga envolvidos em acidentes nas rodovias de jurisdição federal no Estado de Alagoas entre 2007 e 2011. Fonte: DNIT (2011).

Esses números apresentados fornecem um panorama geral da realidade do tema proposto e que para uma compreensão mais efetiva faz-se necessário considerar os fatores básicos mensuráveis causadores dos acidentes nas rodovias brasileiras. 
Assim, para compreender a periculosidade potencial que uma área oferece ao tráfego de produtos químicos perigosos, é essencial prognosticar suas causas e efeitos no espaço. Para isso, a alternativa mais eficiente e capaz de atender a essa necessidade é o mapeamento das áreas que oferecem condições físicas adversas à boa prática da condução dos veículos transportadores de substâncias perigosas.

De acordo com Enomoto (2004) e Friesecke (2004), esse tipo de documento cartográfico é um recurso técnico poderoso no auxílio e no controle e prevenção de acidentes, já que servem de apoio no fornecimento de informações para os programas de redução de danos, possibilitando o zoneamento das áreas com potencial danoso à saúde ambiental.

Diante do exposto, tem-se que o objetivo deste artigo é apresentar as áreas que oferecem níveis de periculosidade associados ao risco ambiental de iminência a acidentes com produtos perigosos na área de influência do trecho alagoano da rodovia BR-101, selecionado para o estudo; fazendo uso de técnicas de geoprocessamento sobre parâmetros naturais e antrópicos.

\section{DISCUSSÃO CONCEITUAL}

Os principais conceitos e definições adotados no presente trabalho dizem respeito ao perigo, a produtos perigosos e a transporte de produtos químicos perigosos, tratados a seguir.

\section{Perigo}

Para Pécurto (2010), Thywissen (2006), Hogan e Marandola Junior (2004), perigo ou periculosidade corresponde à ameaça de eventos extremos, e não raros, serem capazes de causar danos e perdas às populações e ao meio. Isto significa que é um atributo próprio a um fenômeno ou processo imoderado, o qual pode ser de origem natural, tecnológica ou antrópica (UNITED NATIONS, 2004).

Com base nisso, entende-se que os primeiros trabalhos com abordagem geográfica neste âmbito, foram desenvolvidos entre as décadas de 1970 e 1980, e carregavam consigo um mesmo conceito para risco e perigo. Entretanto, o que os tornava conceitualmente diferentes era o entendimento de que "o perigo era o fenômeno estudado e o risco, a perspectiva em que se colocava a abordagem do problema" (MARANDOLA JUNIOR; HOGAN, 2005 p. 32). 
Assim, em vez de se utilizar o impacto como abordagem, prevalecia uma preocupação prognóstica voltada à minimização da incerteza, e isso se dava por meio da mensuração das probabilidades de os perigos acontecerem, sendo, portanto fundamental para diminuir a ocorrência e a intensidade dos desastres.

Nesse aspecto, Burton, Kates e White (1978) ressaltam que os danos sofridos pelo meio e pelas populações, após a ocorrência de desastres, dão-se em função da ocupação dos espaços e pela desconsideração dos impactos e riscos que o uso e/ou a ocupação podem gerar ao homem. Desta forma, entende-se que a escolha por áreas a serem ocupadas ou usadas pelo homem, negligencia os perigos iminentes, sejam eles naturais, antrópicos ou tecnológicos podendo, assim, causar danos, perdas e prejuízos ao meio, às comunidades e aos bens, respectivamente.

Nessas circunstâncias, para Lopes e Barros (2014), os perigos iminentes devem ser associados à ocorrência de eventos e, nesta linha de pensamento, Santos (1997, p. 115-116), por sua vez, remete 0 conceito de perigo à possibilidade de acontecimentos de eventos, oferecendo uma compreensão de que 0 evento é o "ponto" em que o tempo e o espaço se unem em um momento ou em um instante de desconhecimento e de incertezas, em que os atos, quer sejam naturais ou antrópicos, nunca se repetem de forma igual. Nisto, o cenário geográfico se transforma subitamente pois o evento é uma brutalidade sem precedentes, ocasião esta, em que um acontecimento provoca uma crise, e permite uma mudança.

\section{Produtos químicos perigosos}

As definições para os produtos químicos perigosos observadas neste trabalho correspondem àquelas elaboradas pela Companhia de Tecnologia de Saneamento Ambiental de São Paulo (CETESB) e do Departamento de Energia dos Estados Unidos (USDOE).

De acordo com Cetesb (2004) produtos químicos perigosos são aqueles que representam risco para a vida ou saúde humana, o meio ambiente ou outro bem a proteger, a curto ou longo prazo. Os principais produtos perigosos são os gases, líquidos criogênicos, líquidos inflamáveis, oxidantes e peróxidos orgânicos, substâncias tóxicas e substâncias corrosivas. 
Por sua vez, United States Department of Energy (2005), define esses tipos de produtos como todo produto sólido, líquido ou gasoso que sejam tóxicos, inflamáveis, radioativos, corrosivos, quimicamente reativos ou instáveis, por um longo período de armazenamento e em quantidades que representem risco à vida, à propriedade ou ao meio ambiente.

Suplementarmente, outras definições como àquelas estabelecidas pelo Decreto nº. 96.044/1988, pela Lei nº . 8.080/1990, pela Resolução ANTT nº. 420/2004 e pela Norma Brasileira ABNT NBR nº. 10.004:2004, consideram os mesmos elementos presentes nas definições supracitadas, confluindo no entendimento de que os produtos perigosos representam risco à vida, à saúde humana, ao meio ambiente e aos bens, ficando implícito que essa confluência é aplicável desde o processo de fabricação até o seu acondicionamento e transporte.

\section{Transporte de produtos químicos perigosos}

Ao admitir que o transporte de produtos químicos perigosos é parte constituinte na cadeia de produção, pode-se considerá-lo como um fator de risco itinerante, já que o perigo não se encontra localizado em um único lugar, ou seja, na indústria, mas encontra-se em constante movimento; logo, oportuniza riscos a quaisquer lugares ao longo de uma rota.

Por esse motivo, Strauch (2004) diz que, em caso de acidentes envolvendo veículos transportadores de produtos perigosos, as consequências tornam-se de difícil controle devido às descargas súbitas de grande massa de produtos químicos fora e distante de ambientes controlados, a exemplo dos parques industriais; muitas vezes atingindo direta ou indiretamente locais próximos a comunidades, em geral carentes.

Beltrami (2009), discorre que a exposição ocorre quando as populações entram em contato com os produtos perigosos por uma ou mais vias, como a ingestão de água contaminada, o consumo de alimentos contaminados através da cadeia alimentar, a inalação de poeiras tóxicas ou gases provenientes de vazamentos e incêndios, ao contato dérmico com produtos corrosivos ou a abstrusa combinação desses fatores. 
Diante disso, entende-se que mais importante do que dar respostas aos acidentes com produtos perigosos é evitar que eles ocorram. Assim, deve-se ter em vista a questão preventiva da segurança rodoviária, especificamente para esses tipos de produtos, assumindo por finalidade a garantia da integridade do meio ambiente, seus elementos e consequentemente a saúde humana.

\section{ÁREA DE ESTUDO}

Este trabalho adotou como área de estudo uma faixa de 5 quilômetros no entorno do trecho alagoano da rodovia BR-101, delimitação esta, definida pela Comissão Estadual de Prevenção, Preparação e Resposta Rápida aos Acidentes e Desastres de Origem Tecnológica e Natural no Estado de Alagoas, em função da presença de importantes recursos naturais (mananciais e unidades de conservação) na área de influência direta da rodovia. Limita-se ao norte, na divisa dos municípios de Novo Lino/AL e Xexéu/PE, e, ao sul, na fronteira dos municípios de Porto Real do Colégio/AL e Propriá/SE (Figura $4)$.

Situa-se entre as coordenadas geográficas $8^{\circ} 50^{\prime} 26,42$ " e $10^{\circ} 15^{\prime} 23,97^{\prime \prime}$ de latitude sul ao paralelo do Equador e $35^{\circ} 34^{\prime} 54,33^{\prime \prime}$ e $36^{\circ} 52^{\prime} 24,33^{\prime \prime}$ de longitude oeste ao meridiano de Greenwich, estendendose por uma área de aproximadamente $2.370,66 \mathrm{~km}^{2}$ e circunscrita em um perímetro de 483,36 quilômetros, em sentido longitudinal, abrangendo 27 municípios situados na porção leste do estado de Alagoas.
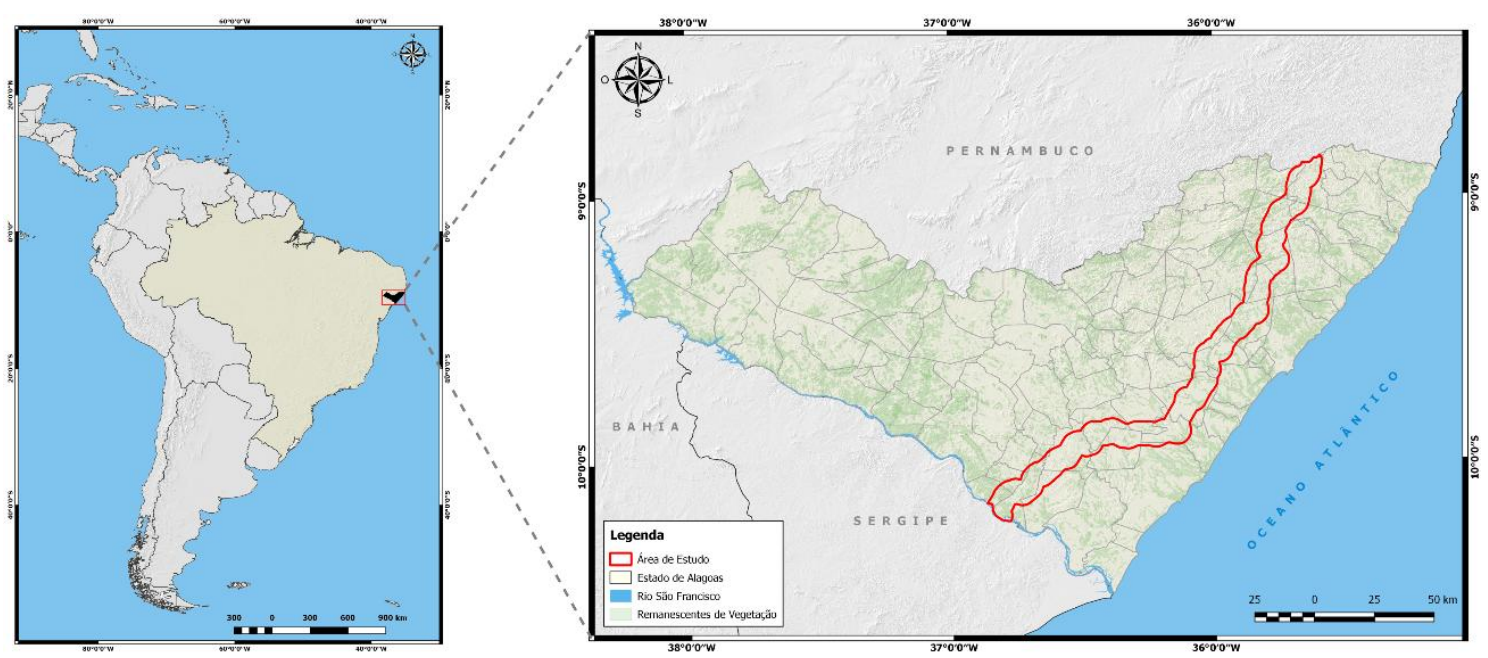

Figura 4. Localização da área de estudo.). 


\section{Caracterização físico-ambiental}

De acordo com a classificação de Thornthwaite e Mather (1955), preponderam os tipos climáticos subúmido e subúmido seco e minoritariamente é influenciada pelo tipo úmido (EMBRAPA, 2012). Para Barros et al (2012), isso favorece temperaturas relativamente elevadas, com médias anuais em torno de $24^{\circ} \mathrm{C}$ a $26^{\circ} \mathrm{C}$, enquanto que as precipitações pluviométricas variam entre 800 e 1.800 mm/ano, marcadas pelo predomínio de ocorrência das chuvas nas estações de outono e inverno.

Hidrograficamente, as 21 bacias hidrográficas abrangidas pela área de estudo apresentam um padrão de drenagem dendrítico e exorreico formado por canais que variam de $1^{\mathrm{a}}$ a $4^{\mathrm{a}}$ ordens, tendo em seus vales morfologias diferenciadas para cada trecho de curso. Os riachos são paralelos, com regime de enxurradas de outono, inverno ou por chuvas ocasionais de primavera.

A litologia é predominantemente dividida em três grandes unidades, que, juntas, correspondem a $2 / 3$ da área estudada, sendo elas: Formação Barreiras (ENb), o Complexo Nicolau-Campo Grande (APng), e a Suíte Intrusiva Itaporanga (NP3).

A morfologia do relevo apresenta poucas diferenciações, com um predomínio da unidade geomorfológica dos Tabuleiros Costeiros que se expressa numa faixa altimétrica de 50 a 100 metros, em média, tendo por característica marcante uma superfície tabuliforme de origem sedimentar, correspondente ao período Neógeno (antigo período Terciário); são cortados transversalmente por rios em cursos paralelos, conferindo variáveis graus de entalhamento, ora com vales estreitos e encostas íngremes, ora com encostas suaves e fundos com várzeas alargadas.

Destaca-se ainda a unidade das Encostas Orientais, que ocupam uma estreita faixa de terras na porção centro-norte do estado e é constituído pelo complexo cristalino do Planalto da Borborema, caracterizado por um extenso bloco estrutural de maciços falhados modelados em rochas cristalinas.

Pedologicamente, dezesseis classes de solos compõem a área em questão; no entanto, três destas possuem relevância devido a sua representatividade, correspondendo aos Argissolos Amarelo (PA), 
Argissolos Vermelho-Amarelo (PvA) e ao Latossolo Amarelo (LA), os quais, somados, compreendem cerca de $80 \%$ da área estudada.

\section{PROCEDIMENTOS METODOLÓGICOS}

A metodologia adotada no trabalho envolveu, além do inventário e elaboração da base de dados físicoambientais provenientes de fontes primárias e secundárias; o levantamento bibliográfico, com vistas ao embasamento teórico-conceitual no tratamento e na elaboração dos respectivos dados; e as atividades de campo, que objetivaram calibrar os planos de informação.

Para a identificação de áreas potencialmente perigosas a proporcionar acidentes com produtos perigosos, foram adotados procedimentos e técnicas operacionais, baseados em um Sistema de Informações Geográficas (SIG), no qual adotou-se os softwares livres QGIS 2.14, SAGA GIS 2.3 e GRASS 7.0.

\section{Obtenção e geração dos dados}

O manual para implementação de planos de ação de emergência para atendimento a sinistros envolvendo o transporte rodoviário de produtos perigosos do Departamento Nacional de Infraestrutura e Transportes (2005), estabelece alguns critérios de emprego das variáveis definidoras para a análise pertinentes aos meios físicos, bióticos e antrópicos na área de influência direta da rodovia, levando em consideração os ecossistemas delimitados em função da extensão do alcance dos impactos decorrentes de possíveis acidentes com produtos perigosos. Entretanto, o aludido documento permite interpretações, possibilitando a adoção de outras variáveis.

Nesse entendimento, visando delimitar as áreas potencialmente perigosas à promoção de acidentes com cargas perigosas, foram elencados os quatro parâmetros identificados como essenciais baseados na realidade local: a) Intensidade Pluviométrica; b) Índice de Sinuosidade da Rodovia; c) Neblina Potencial; d) Concentração de Focos de Queimadas. Estes, portanto, se constituíram como a base de dados geográficos adotada na avaliação por geoprocessamento. 


\section{Elaboração do cartograma de intensidade pluviométrica}

Para a elaboração desse cartograma, foram utilizados os dados vetoriais em formato Shapefile (.SHP) da Precipitação Pluviométrica Média Anual para o Estado de Alagoas e o Índice Xerotérmico do Estado de Alagoas.

O primeiro, pertence ao acervo digital do Zoneamento Agroecológico de Alagoas, elaborado pela Embrapa Solos (BARROS et al, 2012); já o segundo foi elaborado pelo Instituto do Meio Ambiente de Alagoas, seguindo a metodologia de Assis (2015, p. 75), para os dados da Sudene (1990) de pluviometria e temperatura referentes à série de 1912 a 1990.

A construção deste plano de informação seguiu a definição de Crepani, Medeiros e Palmeira (2004), os quais afirmam que, para uma determinada área, o quociente do valor da pluviosidade média anual (em mm) e a duração do período chuvoso (em meses) resultam no aludido índice, expressando-se na seguinte fórmula:

$$
I P=\frac{P M A}{(N D C / 30)}
$$

Onde:

$\mathrm{IP}=$ Intensidade Pluviométrica

PMA = Pluviosidade Média Anual

$\mathrm{NDC}=$ Número de Dias com Chuva

O resultado obtido se apresenta em faixas que variaram de 100 a $268 \mathrm{~mm} / \mathrm{mês}$, classificados em seis intervalos de $28 \mathrm{~mm} /$ mês (Figura 5A), conforme se observa no Tabela 1. 


\begin{tabular}{ccc}
\hline $\begin{array}{c}\text { Faixa Pluviométrica } \\
(\mathbf{m m} / \mathbf{a n o})\end{array}$ & Meses Chuvosos & $\begin{array}{c}\text { Intensidade Pluviométrica } \\
(\mathbf{m m} / \mathbf{m e ̂ s})\end{array}$ \\
\hline 800 a 1.100 & 8 a 9 & 100 a 128 \\
1.100 a 1.400 & 7 a 11 & 128 a 156 \\
1.300 a 1.800 & 8 a 11 & 156 a 184 \\
1.500 a 1.800 & 8 a 11 & 184 a 212 \\
1.500 a 1.800 & 7 a 8 & 212 a 240 \\
1.500 a 1.600 & 6 & 240 a 268 \\
\hline
\end{tabular}

Tabela 1. Valores da pluviometria convertidos em intensidade pluviométrica

\section{Elaboração do cartograma de índice de sinuosidade da rodovia}

Para DNIT (2008), o cálculo desse índice é determinado pela somatória dos ângulos internos das curvas horizontais, enquanto que os valores de gradientes verticais podem ser obtidos pelas diferenças relativas entre distância percorrida e o deslocamento na vertical. No entanto, para tal, exige-se que o mapeamento tenha nível de detalhamento compatível com grandes escalas, por exemplo, 1:5.000 Assim, a geração dos dados neste nível de detalhe configurar-se-ia cartograficamente incongruente com a escala adotada no trabalho.

Entretanto, visando suplantar esse obstáculo, foi adotada uma abordagem compatível com a escala de 1:50.000; através da qual, adaptou-se a metodologia apresentada por Riccomini et al. (2000), empregada no cálculo do índice de sinuosidade dos cursos d'água; portanto, apresenta-se mais simplificada e adequada à escala de trabalho, fornecendo valores próximos aos do método anteriormente descrito.

Essa técnica se baseia na razão entre o comprimento real (em projeção ortogonal) da rodovia e a distância vetorial (comprimento em linha reta) entre os dois extremos da via, e se exprime através da seguinte fórmula:

$$
i S=\frac{L r}{L v}
$$

Onde:

iS $=$ Índice de Sinuosidade 
$\mathrm{Lr}=$ Comprimento Real do trecho da rodovia;

$\mathrm{Lv}=$ Comprimento em linha reta do trecho da rodovia.

Os referidos autores destacam que os índices com valores entre 1,0 e 1,25 indicam que o trecho da rodovia tende a ser retilíneo; entre 1,25 e 1,5 definem que o trecho tende a ser moderadamente sinuoso; entre 1,5 e 2,0 apontam que o segmento tende a ser sinuoso, e os valores superiores a 2,0 indicam que o trecho tende a ser demasiadamente sinuoso (Figura 5B).

Com base nisso, a rodovia BR-101 em Alagoas, correspondente à área da pesquisa, foi segmentada em 16 partes (Tabela 2), seguindo o critério de extensão predominante nos municípios pelo qual perpassa a rodovia. Logo, o valor do índice de sinuosidade é diretamente proporcional à área municipal afetada pela rodovia. Dessa forma, os trechos identificados com seus respectivos índices de sinuosidade foram:

\begin{tabular}{ccc}
\hline Municípios & $\begin{array}{c}\text { Índice de } \\
\text { Sinuosidade }\end{array}$ & $\begin{array}{c}\text { Classificação da } \\
\text { Sinuosidade }\end{array}$ \\
\hline $\begin{array}{c}\text { Campestre, Novo Lino, Matriz de Camaragibe, } \\
\text { Joaquim Gomes, São Luís do Quitunde, Murici, }\end{array}$ & & \\
$\begin{array}{c}\text { Messias, Rio Largo, Feira Grande, Campo Grande, } \\
\text { Igreja Nova, Olho d'Água Grande, São Brás e } \\
\text { Porto Real do Colégio }\end{array}$ & 1,00 a 1,25 & Retilíneo \\
São Miguel dos Campos, Teotônio Vilela, \\
Junqueiro e São Sebastião
\end{tabular}

Tabela 2. Índice de sinuosidade por município abrangido pela rodovia BR-101 no estado de Alagoas

\section{Elaboração do cartograma de neblina potencial}

Embora não tenha sido possível obter dados geográficos sobre a ocorrência de neblina para a área de estudo, em virtude da indisponibilidade desse dado para o Estado de Alagoas, adotou-se como plano de informação os dados correspondentes à Neblina Potencial, uma vez que, o processo de formação de neblina é consequência da relação existente entre umidade do ar, temperatura e evapotranspiração (HUBERT; MENDONÇA, 1990). 
Convém salientar que a adoção deste plano de informação se trata de uma solução genérica, uma vez que, para a formação de neblina, são levados em consideração outros elementos constituintes nesse processo, como a pressão atmosférica, por exemplo. Além do mais, existem quatro tipos de formação deste fenômeno, como a de radiação, de advecção, montanha acima (upslope fog) e de evaporação e mistura.

Assim, a elaboração do cartograma em questão consistiu no cruzamento dos planos de informação de índice efetivo de umidade; temperatura média do ar e evapotranspiração potencial; integrantes da base de dados geográficos da Embrapa (2012) no âmbito do convênio da Secretaria de Estado da Agricultura, Pesca e Aquicultura - Seagri-AL/Embrapa Solos. As classes resultantes foram agrupadas com base nas proximidades dos valores das notas, as quais foram nominadas como Baixo, Médio e Alto Potenciais de ocorrência de neblinas (Figura 5C).

\section{Elaboração do cartograma de concentração dos focos de queimadas}

No estado de Alagoas, cerca de 80\% do traçado da rodovia BR-101 está situado, predominantemente, em áreas agrícolas (pastagens e canaviais), através das quais a produção de fumaça decorrente de queimadas sazonais, se constitui em uma grande ameaça à condução de veículos na via, em face da barreira apresentada à visibilidade do entorno.

Ao considerar a importância da representação cartográfica desse fenômeno, postulou-se a modelagem de dispersão da fumaça; entretanto, segundo Tavares (2009), Eagleman (1991), Benson (1989) e Taseiko et al. (2009), para a elaboração do cartograma de dispersão de poluentes atmosféricos, leva em consideração outros fatores como o relevo da região analisada, a rugosidade do terreno, o tipo de uso do solo, as condições meteorológicas como nebulosidade, pluviosidade, altura da camada de mistura da atmosfera, temperatura, pressão e estabilidade atmosférica, direção e velocidade dos ventos predominantes, além do tipo e quantidade de fonte emissora.

Assim sendo, para a elaboração de um plano de informação que figurasse no rol de cartogramas digitais da avaliação, adotou-se alternativamente a técnica de mapa de calor (heatmap), que é fundamenta no método geoestatístico de estimativa de curvas de densidade. 
Esse método se torna uma opção simples e eficaz na análise do comportamento geográfico dos pontos, com base na sua localização e proximidades, estimando-se, portanto, sua intensidade na área de interesse. Câmara, Davis e Monteiro (2001) explicam que essa técnica se dá em função da contagem de todos os pontos em uma determinada área de influência, ponderando-os pela distância de cada um em relação à localização de interesse.

Para esse fim, foram utilizados os dados do Banco de Dados de Queimadas (BDQueimadas) disponibilizados pelo Instituto Nacional de Pesquisas Espaciais (INPE), no endereço eletrônico: http://goo.gl/2qcNVe. Esses dados correspondem às geolocalizações dos focos de queimadas e foram obtidos no formato Shapefile (.SHP) para o estado de Alagoas, referentes aos anos de 2007 a 2015.

Para se chegar a esse cartograma, necessitou-se adotar uma função e um raio de influência, os quais definem a vizinhança do ponto a ser interpolado, controlando a suavização do modelo gerado.

Cabe dizer que a definição do raio de influência determina a espacialização das curvas estimadas, de modo que, para Soares e Braga (2012), a determinação de um raio muito grande, a superfície parecerá homogênea e amaciada; neste, as características locais serão ocultadas, ao passo que, para um raio pequeno, a superfície tenderá a picos concêntricos, gerando uma superfície descontínua.

Mediante isso, buscando o meio termo neste sentido, foi determinado um raio de influência de 5 quilômetros, fundamentado na média das distâncias registradas por Mariano (2006) que simulou numericamente a dispersão de nanoparticulados liberados pelo antigo lixão de Maceió, mediante combustão dos resíduos sólidos, nas estações de seca e de chuva.

A função algorítmica empregada foi a quártica (biponderada), pois a sua vantagem em relação às demais funções se dá no processo da interpolação, ao atribuir pesos maiores para os pontos mais próximos do que para os pontos mais distantes, o que permite, dessa maneira, um decrescimento gradual e harmonioso.

Assim, obteve-se como resultado o mapa de concentração dos focos de queimadas (Figura 5D), no qual foi estabelecida uma legenda contendo três classes, para representar a densidade dos pontos por raio 
determinado para cada ponto. Com isso, elas foram agrupadas da seguinte maneira: a) inferiores a 15 focos; b) entre 15 e 30 focos; e c) superiores a 30 focos.
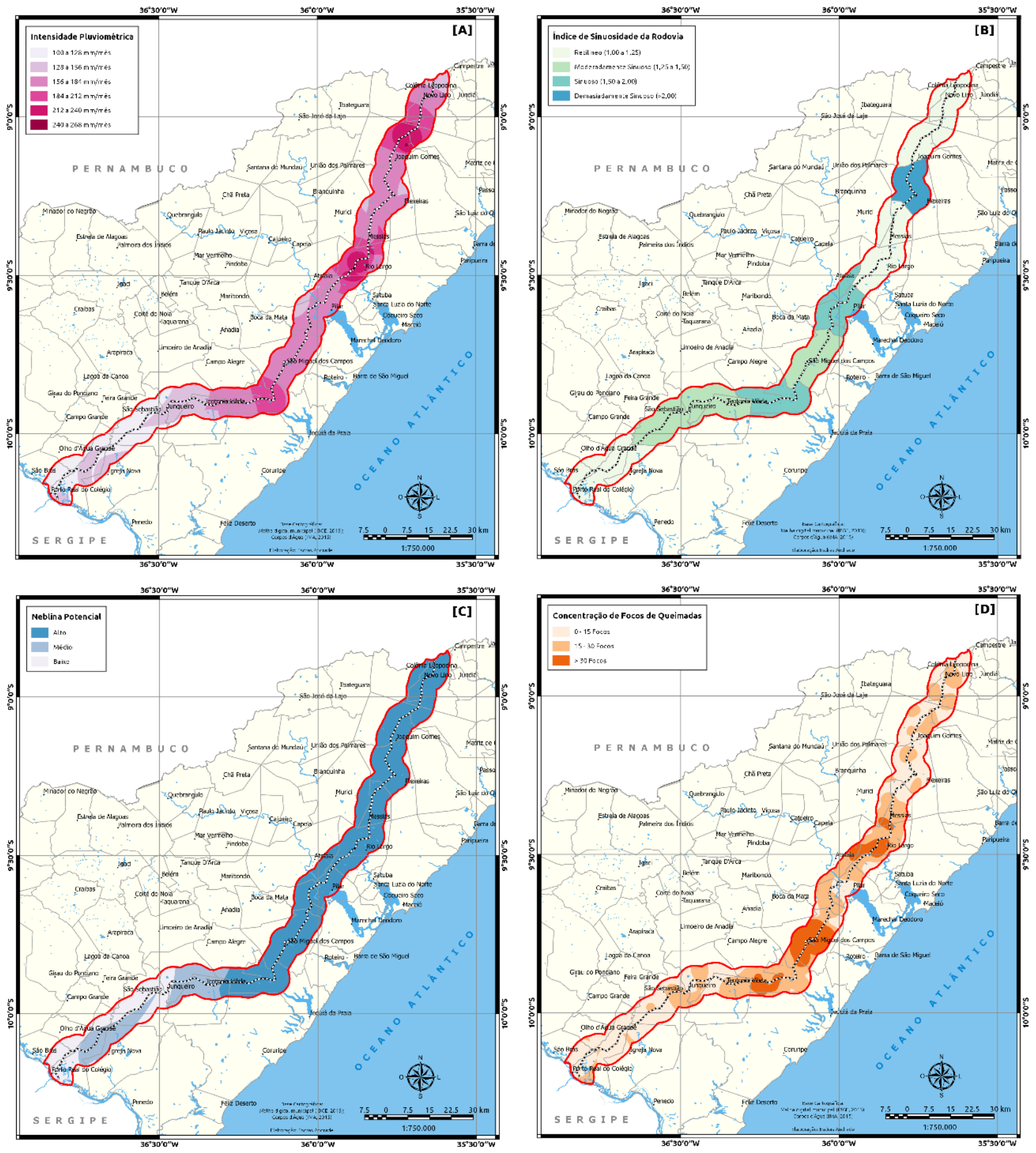

Figura 5. Cartogramas elaborados para a integração do plano de informação das áreas de periculosidade potencial a acidentes com transporte rodoviário de produtos perigosos. [A] Intensidade pluviométrica. [B] Índice de sinuosidade da rodovia. [C] Neblina potencial. [D] Concentração de focos de queimadas

\section{Integração dos dados}


A integração dos dados é entendida, neste estudo, como a conjugação das variáveis selecionadas mediante atribuição de pesos e notas, instruídas pelas planimetrias realizadas previamente para as classes pertencentes à base de dados e pelo conhecimento empírico da área estudada. Em analogia direta, corresponde à Avaliação Ambiental, concebida por Xavier da Silva (2001).

Devido ao seu caráter integrador, o geoprocessamento dispõe de diversas técnicas de integração, sendo a álgebra de mapas a adotada neste estudo. Esta consiste na aplicação de operações aritméticas voltadas à associação de vários planos de informação (variáveis), de modo a obter como resultado classificações que permitem análises diversas. Assim, o emprego da análise multicritério através do algoritmo da média ponderada permitiu agrupar e classificar áreas que contribuem na identificação das zonas perigosas com potenciais de propiciar acidentes com transporte de cargas químicas.

Nas integrações realizadas por meio de média ponderada, cada mapa é ponderado pela utilização de pesos, distribuídos entre as variáveis até se atingir 100\% da responsabilidade pelo fenômeno estudado, segundo o seu grau de importância. Em relação às classes pertencentes a essas variáveis, recebem notas de 0 a 10, conforme a possibilidade de sua associação com a ocorrência do fenômeno estudado.

Assim, foi definido que as classes com uma participação nula na ocorrência do fenômeno estudado recebessem nota 0 ; àquelas com participação quase nula ganhassem notas 1 e 2 , respectivamente. As classes com uma pequena participação na ocorrência do fenômeno estudado receberam notas de 3 e 4 . Já para aquelas com participação média, as notas variaram entre 5 e 6 , e aquelas com grande participação, entre 7 e 8. Nas classes em que as ocorrências eram muito possíveis e extremamente possíveis, foram atribuídas as notas 9 e 10, respectivamente.

De acordo com Calheiros (2000, p. 77), o algoritmo da média ponderada se dá pelo somatório do produto de pesos versus notas para cada célula (pixel) dos planos de informação submetidos à integração, de modo a resultar no mapa síntese para a finalidade desejada.

O algoritmo utilizado é representado pela seguinte expressão:

$$
A_{i j}=\sum_{k=1}^{n}\left(P_{k} \cdot N_{k}\right)
$$


Onde:

Aij = Célula qualquer da matriz

$\mathrm{n}=$ Número de parâmetros envolvidos

$\mathrm{k}=$ Plano de informação

$\mathrm{P}=$ Peso atribuído do parâmetro, no intervalo de 0 a 1

$\mathrm{N}=$ Nota atribuída à categoria encontrada na célula da matriz (0 a 10)

\section{Integração das variáveis para obtenção do mapa de periculosidade potencial}

A Periculosidade Potencial diz respeito à conjugação direta dos dados e representa a potencialidade de atribuir perigo iminente às áreas onde podem ocorrer os acidentes com produtos perigosos.

Para a obtenção desse mapa, foram combinadas o variável Índice de Sinuosidade da Rodovia, Intensidade Pluviométrica, Concentração dos Focos de Queimadas e Neblina Potencial, as quais receberam pesos e notas, conforme Tabela 3.

\begin{tabular}{ccccc}
\hline Variáveis & Pesos & Classes & Notas & $\begin{array}{c}\text { Graus de } \\
\text { Possibilidade }\end{array}$ \\
\hline Índice de & & Retilíneo $(1,00$ a 1,25$)$ & 5 & Médio \\
Sinuosidade & 0,35 & Moderad. Sinuoso $(1,25$ a 1,50$)$ & 5 & Médio \\
da Rodovia & & Sinuoso $(1,50$ a 2,00$)$ & 7 & Alto \\
& & Demasiadamente Sinuoso $(>2,00)$ & 9 & Muito Alto \\
& 100 a $128 \mathrm{~mm} /$ ano & 4 & Baixo \\
Intensidade & 0,25 & 128 a $156 \mathrm{~mm} /$ ano & 5 & Médio \\
Pluviométrica & & 156 a $184 \mathrm{~mm} /$ ano & 6 & Médio \\
& & 212 a $240 \mathrm{~mm} /$ ano & 7 & Alto \\
Concentração de & 240 a $268 \mathrm{~mm} /$ ano & 8 & Alto \\
Focos de & 0,2 & 0 a 15 focos & 9 & Muito Alto \\
Queimadas & & 15 a 30 focos & 4 & Baixo \\
& & $>30$ focos & 7 & Alto \\
Neblina Potencial & 0,2 & Baixo Potencial & 10 & Muito Alto \\
& & Médio Potencial & 2 & Muito Baixo \\
& & Alto Potencial & 5 & Médio
\end{tabular}

Tabela 3.Atribuição de pesos e notas para as variáveis e respectivas classes utilizados na integração da base de dados.

\section{Participação da variável índice de sinuosidade da rodovia na integração dos dados}

A variável Índice de Sinuosidade da Rodovia recebeu peso 0,35, o que corresponde a $35 \%$ de participação na responsabilidade pelo fator de periculosidade, porque, dentre os dados considerados 
para essa integração, é o único que se exprime permanentemente na área de estudo, pelo traçado da própria rodovia BR-101.

As notas foram consideradas de acordo com o grau de possibilidade de envolvimento das classes como fator de perigo à ocorrência de sinistro, sendo balizadas pelas informações prestadas pela Polícia Rodoviária Federal quanto ao tipo do traçado nos eventos de acidentes envolvendo veículos que transportam produtos químicos perigosos (Figura 6).

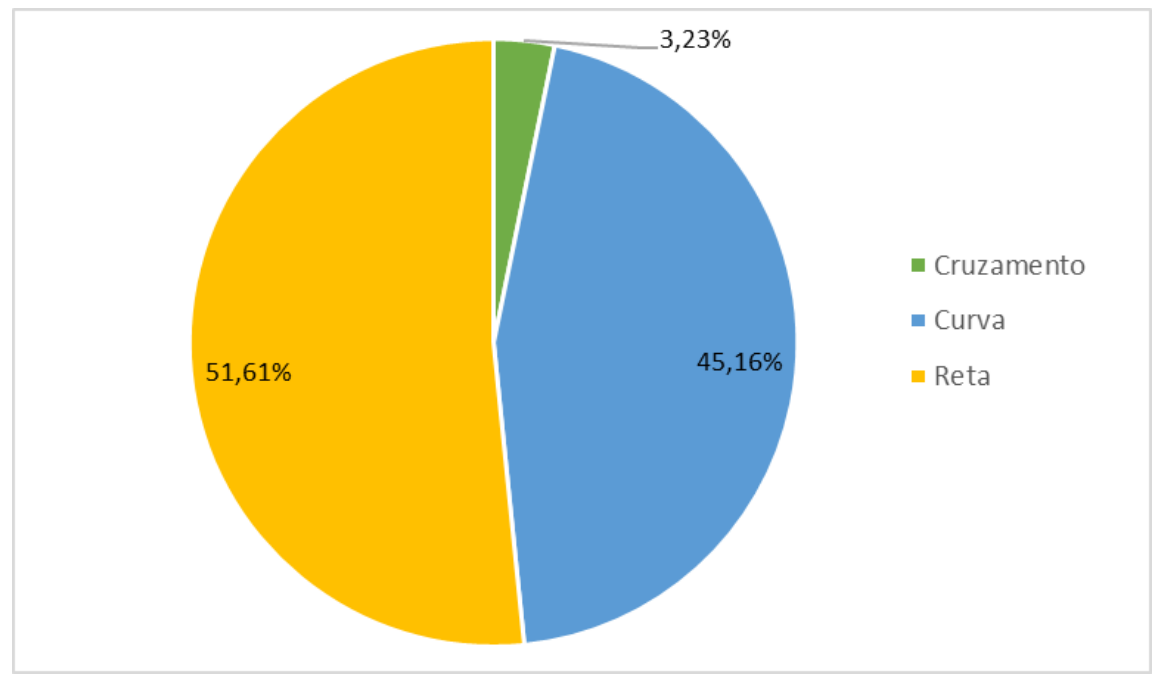

Figura 6. Relação acidentes vs. traçado da rodovia. Fonte: Polícia Rodoviária Federal (2016).

O grau de possibilidade de ocorrência de acidentes em um trecho retilíneo seria quase nulo, mas ao ser ponderado com a informação de que $51,61 \%$ dos sinistros ocorreram em trechos retos, atribuiu-se uma nota 5, elevando-se, assim, o nível de probabilidade desses eventos em segmentos retos da rodovia.

Em relação aos trechos curvilíneos, estes foram divididos nas classes Sinuoso $(1,50-2,00)$ e Demasiadamente Sinuoso $(>2,00)$ e receberam notas 7 e 9 , respectivamente, em função da relação da intensidade angular das curvas e os graus de possibilidade com o fenômeno em questão.

\section{Participação da variável intensidade pluviométrica na integração dos dados}

Esta variável colabora na integração com o peso 0,25 , o que corresponde a $25 \%$ de participação na responsabilidade pelo fator de periculosidade, porque é uma variável que ocorre mais intensamente nas estações apropriadas. 
Além disso, considerou-se também o perigo durante ou após sua ocorrência, como a possibilidade de erosão da rodovia ou encostas, formação de lâmina d'água sobre o asfalto, além da afetação à visibilidade do condutor.

A atribuição das notas foi balizada mediante as informações prestadas pela Polícia Rodoviária Federal quanto ao tipo das condições meteorológicas nos eventos de acidentes que envolvem veículos transportando produtos químicos perigosos (Figura 7).

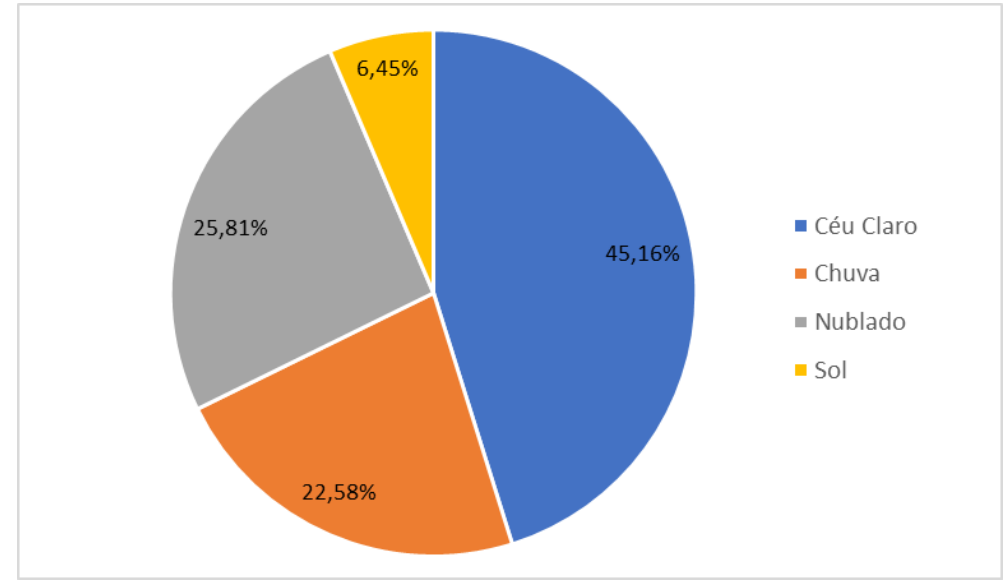

Figura \%. Relação acidentes vs. Condições meteorológicas. Fonte: Polícia Rodoviária Federal (2016)

Ademais, essas notas foram atribuídas de acordo com a gradação da intensidade das chuvas, variando de 4 até a 9, o que corresponde a graus de possibilidade baixo e muito alto, respectivamente; elas, portanto, foram equalizadas pela proporção dos acidentes com TRPP (22,58\%) sob condições meteorológicas de precipitação pluvial.

\section{Participação da variável concentração dos focos de queimadas na integração dos dados}

Esta variável contribui para a integração com o peso 0,2 , o que corresponde a $20 \%$ de participação na responsabilidade pelo fator de periculosidade. Isso acontece porque, igualmente à variável anterior, considerou-se a escala temporal, por ela estar associada às queimadas sazonais nas áreas cultivadas pela cana-de-açúcar, representando aproximadamente $40 \%$ da área estudada. Esse fato constitui fator de perigo pela ameaça à visibilidade dos condutores de veículos nas temporadas de colheita e a possibilidade de incendiar um veículo transportador de produto perigoso, quando perpassa a área atingida pela queimada. 
As notas concedidas às classes variaram de acordo com o registro da incidência dos focos de queimadas e suas representações espaciais, e isso está diretamente ligado à frequência de queimadas, de modo a ocasionar, por conseguinte, fumaça em um período de tempo maior, e não em concentração de fumaça, o que sugere o mapa dessa variável.

Assim, a classe pertinente à concentração de $0-15$ focos recebeu nota 4 , graças a sua vasta extensão espacial, que abrange a 47,30\% da área estudada. A categoria 15-30 focos, obteve nota 7, proporcional à classe anterior, por corresponder basicamente ao dobro de incidência de focos associada a sua representatividade espacial, ou seja, 40,54\% da superfície total analisada. Já a categoria $>30$ focos percebeu uma nota 10, diferenciando-se dos critérios das classes anteriores, isto é, o fator espacial foi analisado inversamente aos demais, o que representa uma maior incidência de focos de queimadas em uma área mais restrita. Isso significa dizer que em áreas onde há uma frequência maior de queimadas agrega-se mais perigo.

\section{Participação da variável neblina potencial na integração dos dados}

Esta variável recebeu peso 0,2 , o que corresponde a $20 \%$ de participação na responsabilidade pelo fator de periculosidade, por ser um dado estimado, não sendo possível precisar sua representação espacial, e porque essa possibilidade de ocorrência se limita às condições meteorológicas do ambiente e

a um determinado horário do dia. É uma variável que possui significância probabilística como fator causador de acidentes.

As notas empregadas corresponderam às das classes obtidas na sua elaboração. Dessa forma, a classe Baixo Potencial recebeu nota 2 por representar um grau de possibilidade de envolvimento muito baixo com o fator de periculosidade à ocorrência de acidentes com TRPP. Esse princípio é reproduzido para as outras duas categorias deste tema.

\section{Elaboração do mapa de periculsoidade potencial}

Antes de proceder à integração dos dados, fez-se necessária a conversão das variáveis do formato vetorial Shapefile (.SHP) para o formato matricial Geotiff (.TIF). 
Em seguida, o procedimento de integração de dados se deu através da aplicação da Calculadora Raster do software QGIS, no qual foi possível construir a expressão matemática que permitiu a combinação das variáveis. Como resultado dessa operação, apresentou-se o mapa sinótico de Periculosidade Potencial, ao se considerar os pesos e as notas atribuídas, conforme explicado anteriormente.

A expressão matemática construída na calculadora Raster para a elaboração do mapa síntese, foi a seguinte:

$$
P P=(S R \times 0,35)+(I P \times 0,25)+(F Q \times 0,20)+(N P \times 0,20)
$$

Onde:

$\mathrm{PP}=$ Periculosidade Potencial

$\mathrm{SR}=$ índice de Sinuosidade da Rodovia

$\mathrm{IP}=$ Intensidade Pluviométrica

$\mathrm{FQ}=$ Concentração de Focos de Queimadas

$\mathrm{NP}=$ Neblina Potencial

\section{RESULTADOS E DISCUSSÃO}

Os resultados ora apresentados dizem respeito à integração simples entre os cartogramas constituintes na base de dados, os quais resultaram no plano de informação de Áreas de Periculosidade Potencial.

\section{Áreas de periculosidade potencial}

O cômputo da média ponderada aplicada às variáveis resultou nas classes expressas através das notas compreendidas entre 3 e 8. Estas, ordenadas da menor para maior, foram agrupadas em três níveis de perigo que podem favorecer os acidentes com TRPP na área analisada; os quais se apresentaram como Baixo, Médio e Alto Potenciais (Figura 8).

Para que isso se tornasse possível, foi realizada a transposição das classes que se encontravam na escala ordinal (quantitativa) para a escala nominal (qualitativa), uma vez que estas permitem agrupamentos de categorias por similaridade. Por essa razão, as notas 3 e 4 foram agrupadas em uma única classe e renomeadas como Baixo Potencial. Seguindo esse mesmo princípio, as notas 5 e 6 foram 
aglutinadas na categoria Médio Potencial e, por fim, as notas 7 e 8 foram coligidas na classe Alto Potencial.

As notas compreendidas de 0 a 2 e de 9 a 10 não foram expressas no resultado da integração, o que significa que não houve representação dos potenciais muito baixo e muito alto, respectivamente.

A partir do exposto, foi possível realizar planimetrias deste plano de informação sobre a sua base de dados constituinte, através do qual procederam-se as mensurações que embasam a análise espacial a seguir.

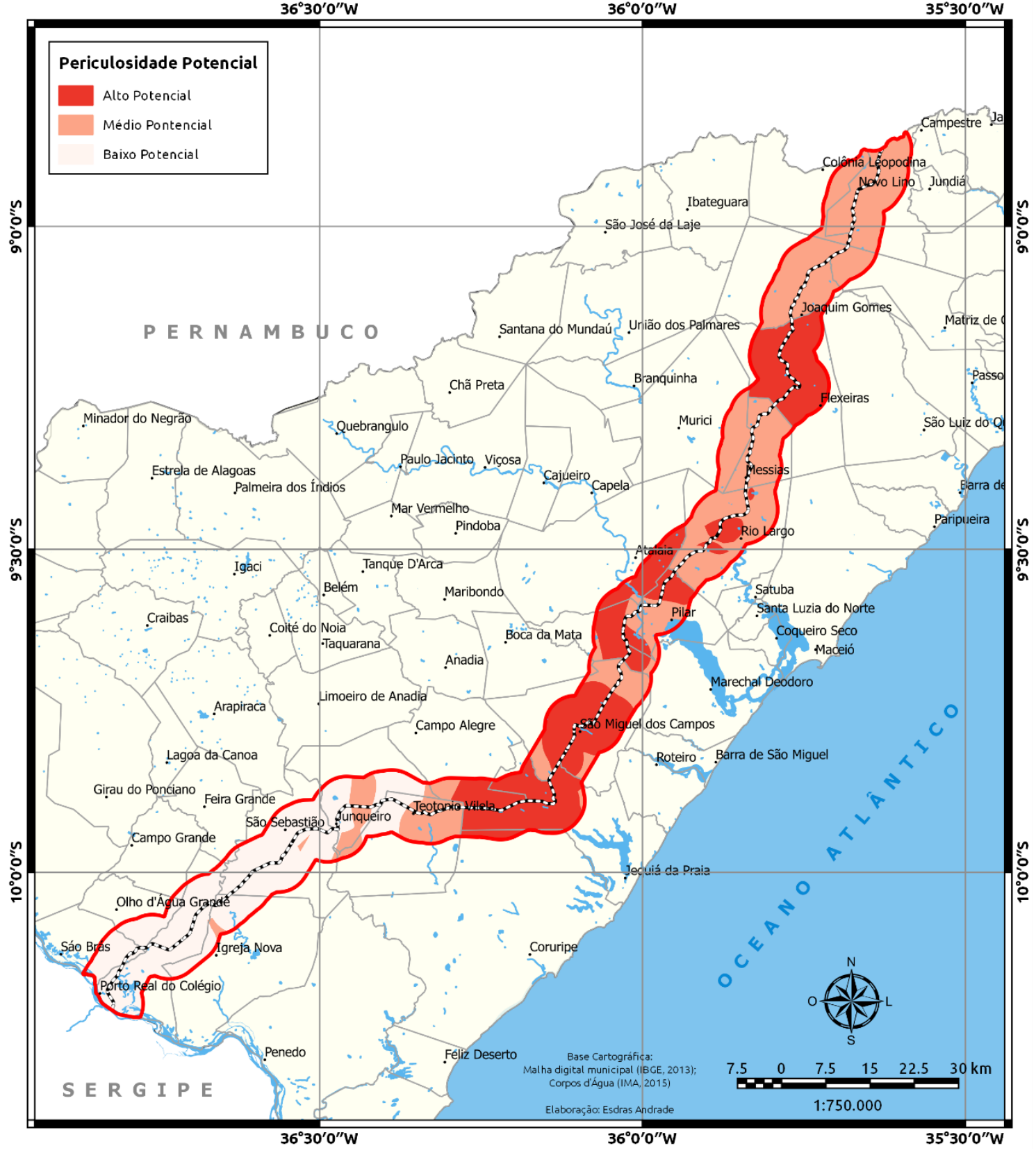

Figura 8. Áreas potenciais a periculosidade de acidentes com produtos perigosos. 
Assim, foi possível identificar que a classe Médio Potencial se sobressai espacialmente em relação às demais, com uma extensão de $982,22 \mathrm{~km}^{2}$, o que corresponde a 41,43\% da superfície total analisada, seguidas das classes Alto e Baixo Potenciais, nesta ordem (Tabela 4)

\begin{tabular}{ccc}
\hline Classes & Área (ha) & Área (\%) \\
\hline Alto Potencial (Notas 7 e 8) & 743,20 & 31,35 \\
Médio Potencial (Notas 5 e 6) & 982,22 & 41,43 \\
Baixo Potencial (Notas 3 e 4) & 645,24 & 27,22 \\
\hline Totais & $\mathbf{2 . 3 7 0 , 6 6}$ & $\mathbf{1 0 0 , 0 0}$ \\
\hline
\end{tabular}

Tabela 4. Planimetria das áreas de periculosidade potencial.

\section{Áreas com alta periculosidade potencial (notas 7 e 8)}

Esta classe abrange $31,35 \%\left(743,20 \mathrm{~km}^{2}\right)$ da área total analisada, expressando-se através de 3 grandes partições preponderantes. Na porção norte, situa-se entre os municípios de Messias e Joaquim Gomes; no centro, compreende partes dos municípios de Atalaia, Pilar e Boca da Mata; e entre São Miguel dos Campos e Jequiá da Praia.

De modo geral, essas áreas estão sob influência de um regime de média intensidade pluviométrica, onde $67,68 \%\left(503,02 \mathrm{~km}^{2}\right)$ pertencem à classe 156 a $184 \mathrm{~mm} /$ ano e $15,16 \%\left(112,67 \mathrm{~km}^{2}\right)$ à classe 184 a 212 mm/mês (Figura 9A). Associado a essa constatação, verifica-se que todas as manifestações de alta periculosidade pertencem às áreas com alto potencial de ocorrência de neblina (Figura 9B).
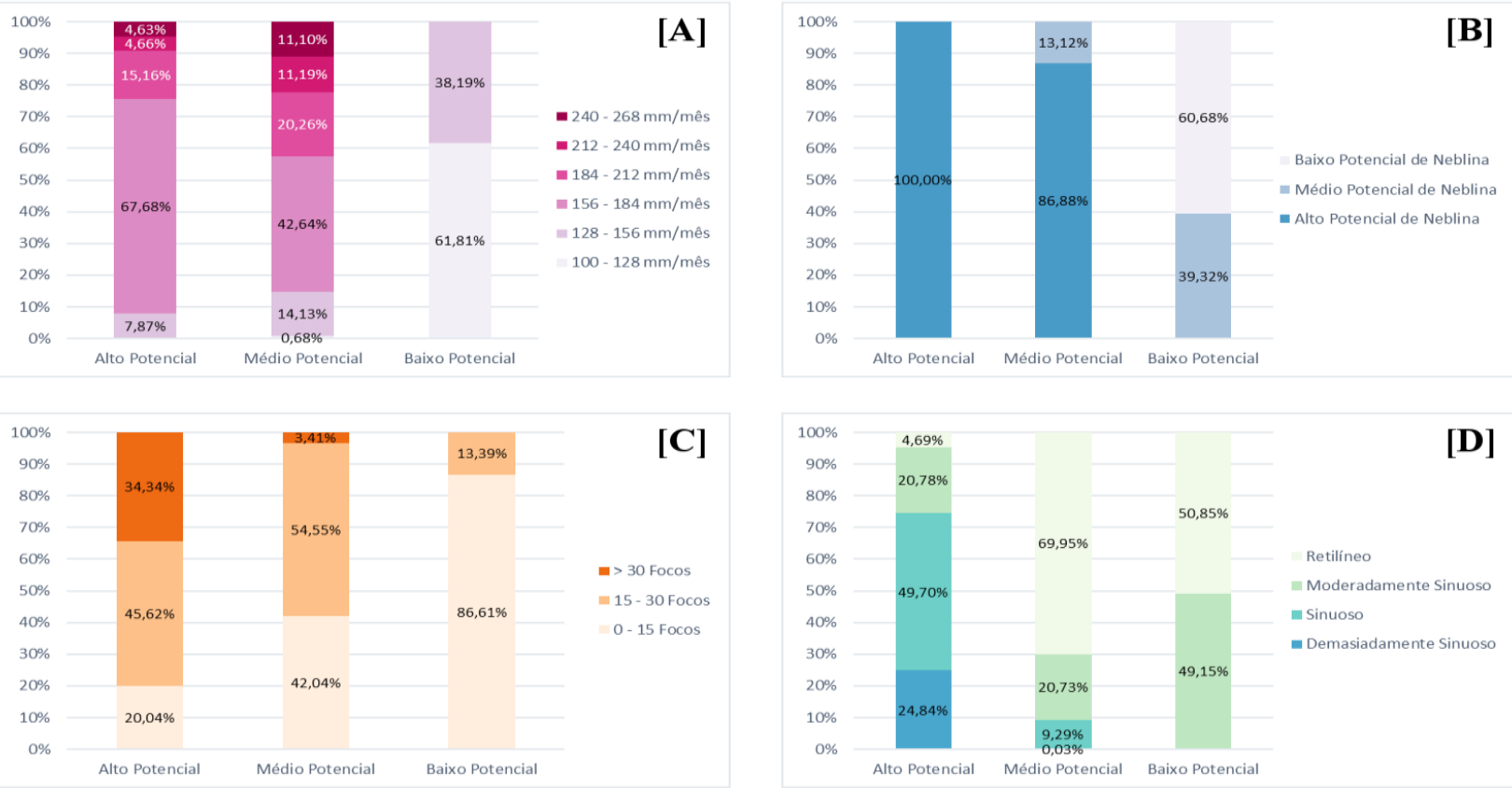
Figura 9. Distribuição percentual dos parâmetros da base de dados no mapa de periculosidade potencial: [A] Intensidade Pluviométrica. [B] Neblina Potencial. [C] Concentração dos Focos de Queimadas. [D] Índice de Sinuosidade da Rodovia.

No que se refere à distribuição percentual da sinuosidade da rodovia, cerca de $553,95 \mathrm{~km}^{2}(75 \%)$ desta classe efetua-se em trechos sinuosos e demasiadamente sinuosos (Figura 9D). Em relação à concentração dos focos de queimadas na área de abrangência da alta periculosidade potencial, cerca de $255,19 \mathrm{~km}^{2}(34,34 \%)$ situa-se em regiões que detêm muita possibilidade de ocorrência de fumaça, com concentração de valores superiores a 30 focos (Figura 9C), decorrentes do registro histórico de focos de queimadas sazonais nas áreas agrícolas; nesse caso, a queima das lavouras de cana-de-açúcar.

Diante deste cenário, recomenda-se a adoção de meios de redução de velocidade dos veículos nos trechos que oferecem alto grau de perigo a acidentes. Associado a isto, é de bom alvitre a retificação dos locais mais sinuosos da rodovia, quando da execução do projeto de sua duplicação. Recomenda-se, ainda, a aplicação da lei estadual nº. 7.454/2013 e do decreto federal nº. 2.661/1998 que legislam sobre o emprego do fogo como método despalhador e facilitador do corte de cana-de-açúcar em áreas passíveis de mecanização da colheita.

\section{Áreas com média periculosidade potencial (notas 5 e 6)}

Ocupam uma área de 982,22 km², o que corresponde a 41,43\% da superfície total analisada. É a classe que se sobressai espacialmente em relação às demais. Sua extensão geográfica se destaca na porção norte, compreendida entre os municípios de Novo Lino, Colônia Leopoldina, Matriz de Camaragibe e Joaquim Gomes. Há ainda outras 5 pequenas manifestações na porção central, nos territórios municipais de Pilar, São Miguel dos Campos, Teotônio Vilela e Junqueiro.

A intensidade pluviométrica que predomina nesta categoria de periculosidade potencial é considerada de baixa a média intensidade e correspondem às faixas 100 a 128, 128 a 156, 156 a 184 mm/ano que, somadas, respondem por $57,45 \%$, ou seja, $564,29 \mathrm{~km}^{2}$ do total analisado. Quanto à ocorrência de fumaça, a classe em questão se estabelece em um cenário regido pela média possibilidade deste 
fenômeno, representado pela concentração de 15 a 30 focos de queimadas com 535,80 km², o que representa $54,55 \%$ da área estudada; estando relacionado à região predominantemente agrícola sob influência da pecuária extensiva que emprega como técnica de renovação do pasto o emprego de fogo.

Em relação à neblina potencial, essas áreas se estabelecem numa região de alto potencial de ocorrência de neblina, ocupando uma extensão de $86,88 \%\left(853,35 \mathrm{~km}^{2}\right)$ da área total desta classe. Referente ao índice de sinuosidade da rodovia, há um predomínio de trechos retilíneos e moderadamente sinuosos. Isto ocupa uma área de $890,66 \mathrm{~km}^{2}(90,67 \%)$.

Com base nisso, sugere-se uma fiscalização mais incisiva por parte dos entes competentes, com aplicação de punições administrativas e cíveis, visando coibir a prática de queima de pasto. Recomenda-se também, a melhoria da sinalização nos trechos retilíneos, além do incentivo à instalação de novos postos de apoio, proporcionando aos condutores mais locais de espera pela dissipação da neblina e fumaça.

\section{Áreas com baixa periculosidade potencial (notas 3 e 4)}

Com a menor cobertura areal, ocupando $645,24 \mathrm{~km}^{2}$, representando $27,22 \%$ da área de estudo, esta classe se estende por toda porção sul abrangendo partes dos municípios de Junqueiro a São Brás e Porto Real do Colégio.

Toda essa área está sob o alcance das baixas faixas de intensidade pluviométrica (100 a 128 e 128 a $156 \mathrm{~mm} / \mathrm{mês}$ ) e se dão em função do clima subúmido seco, típico da zona de transição entre os biomas Mata Atlântica e Caatinga no estado de Alagoas. Esta mesma área apresenta predominantemente baixo registro de focos de queimadas sazonais, relativos à faixa de concentração 0 a 15 focos, de forma que se distribui por $558,84 \mathrm{~km}^{2}(86,61 \%)$ da classe em questão.

No que concerne ao potencial de incidência de neblina, cerca de $61 \%\left(391,52 \mathrm{~km}^{2}\right)$ da área desta categoria situa-se em regiões de baixo potencial à incidência deste fenômeno e isto se deve, mais uma 
vez, ao clima influente no local. Ressalta-se que, o segmento da rodovia inserido na categoria em questão é considerado retilíneo a moderadamente sinuoso, sendo $328,10 \mathrm{~km}^{2} \quad(50,85 \%)$ correspondente ao primeiro tipo de traçado e $317,14 \mathrm{~km}^{2}(49,15 \%)$ ao segundo tipo.

Diante disso, as condições meteorológicas e antrópicas mostram-se próximas às condições ideais de áreas que apresentam potencial nulo à periculosidade relacionada a acidentes com transporte rodoviário de produtos químicos perigosos.

\section{CONCLUSÕES}

O artigo ora exposto tratou do perigo, correspondente à primeira parte da modelagem conceitual de áreas de risco. Este conceito é composto por seus elementos básicos: perigo, suscetibilidade, vulnerabilidade e elementos expostos, que se traduzem por fragilidade do ambiente e sítios vulneráveis aos danos decorrentes de desastres de natureza química transportadas por meio terrestre.

Ao buscar exaurir o a compreensão dos fatores de periculosidade, constata-se a possibilidade de incremento de outros elementos a fim de fornecer uma melhor acurácia mais refinada aos resultados das áreas potencialmente perigosas. Além dos que foram adotados neste trabalho, recomenda-se o uso de dados das condições de conservação da rodovia; do estado das sinalizações verticais e horizontais e do atropelamento de fauna silvestre e doméstica.

A partir das informações aqui expostas, é evidente que a compartimentação da área se dá em função dos pesos e notas atribuídos aos planos de informação, através do qual, qualifica os parâmetros de intensidade pluviométrica e de sinuosidade da rodovia como aqueles que carregam a responsabilidade de definir os trechos de maior periculosidade, influenciando diretamente na probabilidade de ocorrência de acidentes com produtos perigosos.

\section{REFERÊNCIAS}

ASSIS, José Santino de. Primícias da ciência geofitoambiental. Maceió: Queima-bucha, 2015. 336 p. 
BARROS, Alexandre Hugo Cezar et al. Climatologia do Estado de Alagoas. Recife: Embrapa, 2012. 33 p. Disponível em: <http://goo.gl/iI3QTj>. Acesso em: 21 nov. 2015.

BELTRAMI, Aramis Cardoso Acidentes com produtos perigosos: análise de dados dos sistemas de informações como subsídio às ações de vigilância em saúde ambiental. 2009. 46 f. Dissertação (Mestrado em Saúde do Trabalhador e Ecologia Humana) - Escola Nacional de Saúde Pública, Rio de Janeiro, 2009. Disponível em: < https://goo.gl/V7s0nY >. Acesso em: 05 jan. 2016.

BENSON, Paul. CALINE4: a dispersion model for predicting air pollutant concentrations near roadways. California: Department of Transportation, CA, 1989. (Report no. FHWA/CA/TL-84/14).

BURTON, Ian; KATES, Robert William; WHITE, Gilbert Fowler. The environment as hazard. New York: Oxford University, 1978. 240p.

CALHEIROS, Silvana Quintella Cavalcanti. Turismo versus agricultura no litoral meridional de Alagoas. Rio de Janeiro: UFRJ. 2000. v.1 e 2. Tese (Doutorado em Geografia - Centro de Ciência Exatas e da Natureza) Universidade Federal do Rio de Janeiro, Rio de Janeiro.

CÂMARA, Gilberto; DAVIS, Clodoveu; MONTEIRO, Antônio Miguel Vieira. (Org.). Introdução à ciência da geoinformação. São José dos Campos: Inpe, 2001. 346 p. Disponível em: <http://goo.gl/oymLaC>. Acesso em: 25 jun. 2015.

COMPANHIA AMBIENTAL DO ESTADO DE SÃO PAULO. Emergências químicas. São Paulo, 2004. Disponível em: <https://goo.gl/eS8AvU >. Acesso em: 3 fev. 2016.

CONFEDERAÇÃO NACIONAL DO TRANSPORTE (Brasil). Anuário CNT do Transporte. 2016. Disponível em: <http://goo.gl/bGKLAU >. Acesso em: 7 jul. 2016.

COSTA, Marcos Aurélio da. O transporte de produtos perigosos no Brasil. 2013. Disponível em: < https://goo.gl/uaQYIL $>$. Acesso em: 9 jul. 2016.

CREPANI, Edison; MEDEIROS, José Simeão de; PALMEIRA, Alessandro Ferraz. Intensidade pluviométrica: uma maneira de tratar dados pluviométricos para análise da vulnerabilidade de paisagens à perda de solo. São José dos Campos: Inpe, 2004. 30 p. Disponível em: <http://goo.gl/8Dmflt>. Acesso em: 05 jan. 2016.

DEPARTAMENTO NACIONAL DE INFRAESTRUTURA E TRANSPORTES (Dnit). Análise e tratamento estatístico dos resultados de contagens de tráfego: determinação das velocidades médias de operação para o ano de 2006. Brasília, DF 2008. 72 p. (Listagem das velocidades médias de operação). Disponível em: < http://goo.gl/3w8qs1 >. Acesso em: 6 jan. 2016.

DEPARTAMENTO NACIONAL DE INFRAESTRUTURA E TRANSPORTES (Dnit). Anuário estatístico das rodovias federais 2010: acidentes de trânsito e ações de enfrentamento ao crime. Brasília, DF, 2011. 687 p. Disponível em: <https://goo.gl/5nh5dW>. Acesso em: 26 abr. 2017.

DEPARTAMENTO NACIONAL DE INFRAESTRUTURA E TRANSPORTES (Dnit). IPR-711: manual rodoviário de conservação, monitoramento e controle ambientais. 2 ed. Rio de Janeiro: Ministério dos Transportes, 2005 a. 68 p.

EAGLEMEN, Joe. R. Air pollution meteorology. Lenexa: Trimedia Publishing Company, 1991. 255 p.

ENOMOTO, Carolina Ferreira. Método para elaboração de mapas de inundação: estudo de caso na bacia do rio Palmital, Paraná. 2004. 132 f. Dissertação (Mestrado em Engenharia de Recursos Hídricos e Ambiental) - Universidade Federal do Paraná, Curitiba, 2004. Disponível em: <https://goo.gl/5G865i >. Acesso em 26 abr. 2017. 
EMPRESA BRASILEIRA DE PESQUISA AGROPECUÁRIA - EMBRAPA. Centro Nacional de Pesquisa de Solos. Unidade de Execução de Pesquisa e Desenvolvimento em Recife. Mapa pluviométrico do estado de Alagoas. In: Zoneamento agroecológico de Alagoas. Recife: Convênio SEAGRI-AL, EMBRAPA, Solos, nº 10200.09/0134-5. 2012.

FRIESECKE, Fran. Precautionary and sustainable flood protection in germany: strategies and instruments of spatial planning. Proceedings of 3rd FIG Regional Conference, Jakarta, 2004. Proceedings... Jakarta, 2004. Disponível em: <https://goo.gl/AcJUOc $>$. Acesso em 30 abr. 2017.

HOGAN, Daniel Joseph; MARANDOLA JÚNIOR, Eduardo. Natural hazards: o estudo geográfico dos riscos e perigos. Ambiente \& Sociedade, Campinas, v. 7, n. 2, p.95-109, 2004. Semestral. Disponível em: < https://goo.gl/RsNBQB $>$. Acesso em: 5 fev. 2016.

HUBERT, Laurence; MENDONÇA, Francisco de Assis. Aplicação de uma imagem landsat MSS ao estudo de clima local Pantanal Matogrossense/MS. Semina: Tech. Ex., Londrina, v. 11, n. 4, p.166-169, 15 dez. 1991. Disponível em: <http://dx.doi.org/10.5433/1679-0375.1990v11n4p166>. Acesso em: 5 fev. 2016.

INSTITUTO DE LOGÍSTICA E SUPPLY CHAIN (Rio de Janeiro). Panorama ILOS: Custos logísticos no Brasil. Rio de Janeiro: Ilos, 2016.

LOPES, Camila Santos Doubek; BARROS, Mirian Vizintin Fernandes. Análise de risco social e tecnológico em gráfica de pequeno porte em Londrina/PR/Brasil. In: LOURENÇO, L. Multidimensão e territórios de risco. Guimarães: Imprensa da Universidade de Coimbra, 2014. p. 469-473. Disponível em: <https://goo.gl/3aBVcB >. Acesso em: 25 abr. 2016.

MARANDOLA JUNIOR, Eduardo; HOGAN, Daniel Joseph. Vulnerabilidades e riscos: entre geografia e demografia. Revista Brasileira de Estudos da População, São Paulo, v. 22, n. 1, p.29-53, jun. 2005. Disponível em:

<https://goo.gl/jDfvC1 $>$. Acesso em: 4 mar. 2016.

MARIANO, Glauber Lopes. Simulação numérica da dispersão dos poluentes H2S e NH3 provenientes do lixão de Maceió-AL nas épocas seca e chuvosa: estudo de casos. 2006. 170 f. Dissertação (Mestrado em Meteorologia) - Instituto de Ciências Atmosféricas, Universidade Federal de Alagoas, Maceió, 2006. Disponível em: < http://goo.gl/L56BCJ>. Acesso em: 15 mar. 2016.

PÉCURTO, Patrícia Cristina Fernandes. Criação de um modelo para a implementação de um sistema de informação geográfica, à escala nacional, para a gestão da cartografia municipal de risco. 2010. 53 f. Dissertação (Mestrado Ciências Sociais e Humanas,) - Departamento de Geografia e Planejamento Regional, Universidade Nova de Lisboa, Lisboa, 2010. Disponível em: < https://goo.gl/l5t5DL>. Acesso em: 6 set. 2015.

RICCOMINI, Claudio. GIANNINI, Paulo César F.; MANCINI, Fernando. Rios e processos aluviais. In: DECIFRANDO a Terra. São Paulo: Oficina de Textos, 2000.568 p.

SANTOS, Milton. A natureza do espaço: técnica e tempo, razão e emoção. 2. ed. São Paulo: Hucitec, 1997, 308 p.

SOARES, Izabele Domingues; BRAGA, Altemir da Silva. Caracterização do mapa de Kernel para avaliar a distribuição do mogno (Swietenia macrophylla King.) na floresta estadual do Antimary. In: REUNIÃO ANUAL DA REGIÃO

BRASILEIRA DA SOCIEDADE INTERNACIONAL DE BIOMETRIA, 57., 2012, Piracicaba. Anais... Piracicaba: Rbras, 2012. p. 1-5. Disponível em: <http://goo.gl/S0aQdm>. Acesso em: 23 jul. 2016.

STRAUCH, Carlos Eduardo. Acidentes com produtos químicos perigosos no transporte rodoviário no estado do Rio de Janeiro: propostas de melhoria nas ações que visam respostas emergenciais. 2004. 238 f. Dissertação (Mestrado em Engenharia) - Faculdade de Engenharia, Universidade do Estado do Rio de Janeiro, Rio de Janeiro, 2004. Disponível em: <https://goo.gl/hLBgoJ >. Acesso em: 5 nov. 2015. 
SUPERINTENDÊNCIA DO DESENVOLVIMENTO DO NORDESTE (Brasil). Dados pluviométricos mensais do Nordeste: Estado Alagoas. Recife, 1990. 2 v. (Brasil. SUDENE. Pluviometria, 7).

TASEIKO, Olga V. et al. Air pollution dispersion within urban street canyons. Atmos. Environ., Oxford, v. 43, 2009, p. $245-252$.

THORNTHWAITE, Charles Warren; MATHER, John Russell. The water balance. Publication in Climatology, Laboratory of Climatology, Centerton, v. 8, n.1. 1955.

THYWISSEN, Katharina. Components of risks: a comparative glossary. Bonn: United Nations, 2006. 52 p. Disponível em: <https://goo.gl/Bbm0FG >. Acesso em: 6 fev. 2016.

UNITED NATIONS. Living with risk: a global review of disaster reduction initiatives. New York: United Nations, 2004. 457 p. Disponível em: < https://goo.gl/A8xF60>. Acesso em: 6 fev. 2016.

UNITED STATES OF AMERICA. Department of Energy. Environmental report for the american centrifuge plant. 4. ed. Pinketon, 2005. 409 p. Disponível em: < https://goo.gl/IhgMH9>. Acesso em: 31 jan. 2016. Acesso em: 7 jul. 2016.

XAVIER DA SILVA, Jorge. Geoprocessamento para análise ambiental. Rio de Janeiro: J. Xavier da Silva, 2001. 228p. 